Creating Productive and Upcoming Sport Education Profesional Hmzanwadi University

Vol.4, No.2, Desember 2021, Hal. 204-209

e-ISSN 2614-8781

\title{
PENINGKATAN SENAM LANTAI MERODA DENGAN MODEL COOPERATIVE LEARNING TIPE CIRCUIT LEARNING
}

\author{
Ratno Susanto ${ }^{1}$, Achmad Afandi ${ }^{2}$ \\ email: $\underline{\text { ratnoexecellent@gmail.com }}{ }^{1}, \underline{\text { achmad_afandi@budiutomomalang.ac.id }}{ }^{2}$ \\ 1,2 Program Studi Pendidikan Jasmani Kesehatan dan Rekreasi, Fakultas Pendidikan Ilmu Eksakta dan \\ Keolahragaan, IKIP Budi Utomo
}

\begin{abstract}
Abstrak
Eksplorasi ini bertujuan peningkatan senam lantai meroda melalui cooperative learning tipe circiut learning untuk Madrsah Tsanawiyah Nurul Huda Dau sebab kurangnya minat siswa yang mengikutti senam lantai meroda dan membutuhkan banyak model pembelajaran hingga menarik minat siswa untuk berolahraga. Proses pembelajaran yang membutuhkan waktu untuk prestasi demi mencapai nilai kkm eksplorasi perlu dilakuakan dan dikembangkan demi tercapainya hasil belajar yang diperoleh demgan kemampuannya. Eksplorasi ini ialah Penelitian Tindakan Kelas(PTK). Eksplorasi ala lakukan dengan 25 siswa. Adapun eksplorasi menggunakan observasi, sikulus I, siklus II, pelaksanaan tindakan, dan refleksi. Instrumen eksplorasi menguntukan saat eksplorasi ialah rubrik penilaian gerak meroda(KI 3: Psikomotorik) dan lembar (KI 4: Kognitif). Teknik analisis data eksplorasi mengukur plus meraih hasil belaja serta menggunakan analisis data kuantitatif. Hasil eksplorasi dalam pembelajaran 10 siswa tuntas 15 siswa tidak tuntas belajar. Siswa diberikan media cooperative learning tipe circuit learning sebagai alat meroda hasil belajar lazimnya dari 25 siswa diperoleh hasil belajar 80\%. Kesimpulan bahwa eksplorasi pada siklus II tampak eskalasi efek belajar dari 25 siswa sebanyak $74 \%$
\end{abstract}

Kata kunci: meroda, circuit learning

\begin{abstract}
.
This exploration aims to improve wheelchair gymnastics through cooperative learning type circuit learning for Madrasah Tsanawiyah Nurul Huda Dau due to the lack of interest of students who participate in wheelchair gymnastics and require many learning models to attract students' interest in exercising. The learning process that requires time for achievement to achieve the KKM value of exploration needs to be carried out and developed to achieve the learning outcomes obtained with their abilities. This exploration is Classroom Action Research (CAR). Do-it-yourself exploration with 25 students. The exploration uses observation, cycle I, cycle II, action implementation, and reflection. Exploration instruments that are used during exploration are the rubric for assessing the wheeling motion (KI 3: Psychomotor) and sheets (KI 4: Cognitive). Exploratory data analysis techniques measure plus achieve learning outcomes and use quantitative data analysis. The results of exploration in learning 10 students completed 15 students did not complete learning. Students are given a circuit learning type of cooperative learning media as a means of moving learning outcomes, usually, from 25 students, $80 \%$ of learning outcomes are obtained. The conclusion is that exploration in cycle II shows an escalation of the learning effect of 25 students as much as $74 \%$.
\end{abstract}

Keywords: wheeling, circuit learning

Journal Pendidikan Jasmani Kesehatan \& Rekreasi (PORKES) |204 


\section{A. Pendahuluan}

Pentingnya pendidikan jasmani, kesehatan, dan rekreasi untuk siswa/ peserta didik sangatlah perlu diperhatikan. Sebab itu bagian dari pendidikan karakter untuk menumbuhkan jiwa yang sportif, serta mengembangkan bakat dan minat siswa untuk berprestasi. Dalam proses pembelajaran pendidikan jasmani, kesehatan, dan rekreasi banyak heterogen cabang olahraga dan banyak metode pembelajaran untuk pendidikan jasmani. Metode pembelajaran untuk siswa di Madrasah Tsanawiyah Nurul Huda Dau memakai cooperative learning tipe circiut learning. Cooperative learning tipe circuit learning ialah memusakakan kans bagi peserta didik dari beraneka lingkungan dan kondisi yang berbeda untuk bekerja dengan saling bergantung pada tugas akademik dan melalui penghargaan kooperatif siswa akan belajar menghargai satu sama lain menurut Ibrahim dkk, dalam Faturrohman (2015:48). Berdasarkan pendapat pakar di atas songsong persepsi bahwa circuit learning ialah pembelajaran yang memaksimalkan pemberdayaan pikiran dan perasaan dengan pola penambahan (adding) dan pengulangan (repetition) yang diterapkan dengan pola yang sama setiap hari kepada siswa. Pola penambahan (adding) dalam circuit learning adalah guru membuat peta konsep dalam menjelaskan materi pembelajaran kepada siswa, kemudian ketika ingin melanjutkan materi pembelajaran pada pertemuan berikutnya guru menambahkan bagian cabang peta konsep yang baru dari cabang peta konsep yang sudah dipelajari pada pertemuan sebelumnya sesuai dengan materi yang akan dipelajari. Sebab adanya circuit learning model pembelajaran bisa menjadi hidup auranya, siswa bisa bersemangat dalam hal pembelajaran olahraga disekolah serta tumbuhnya karakter siswa untuk aspek afektif, serta psikomotorik yang lebih baik. Dari sini bahwa muncullah rumusan masalah bahwa di Madrasah Tsanawiyah Nurul Huda Dau kurangnya model- model pembelajaran dalam cooperative learning untuk senam lantai gerak meroda dan peneliti ingin menghasilkan model pembelajaran circiut learning untuk pembelajaraan efektif dan efisien.

\section{B. Metode}

Eksplorasi ini ialah Penelitian Tindakan Kelas (PTK). Bertujuan menjelang meluaskan penelahan senam lantai gerak meroda via circuit learning siswa kelas 7 Madrasah Tsanawiyah Nurul Huda Dau, observasi hasil belajar dievaluasi akhir RPP. Analisis ini menggunakan deskriftif kuantitatif dengan presentase .

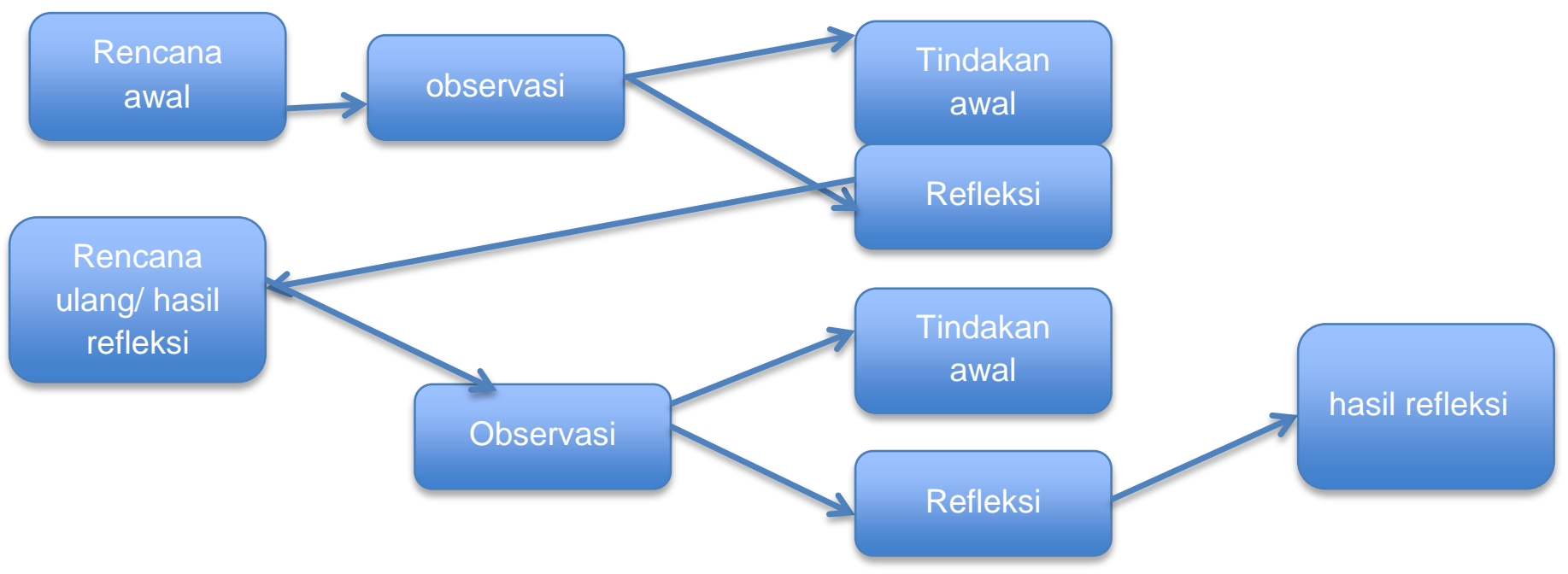

Gambar 1. Desain Eksplorasi PTK 


\section{Hasil dan Pembahasan}

Hasil

Dalam kondisi awal memang banyaknya siswa yang kurang signifikan, berdasarkan diagram dari hasil penilaian baik dari afektif maupun psikomotori dan kognitif perlunya adanya variasi model pembelajaran dalam senam lantai dari hasil yang didapat kurangnya siswa untuk belajar dengan model ya menuntun, sehingga grafik pada diagram sebagai berikut.

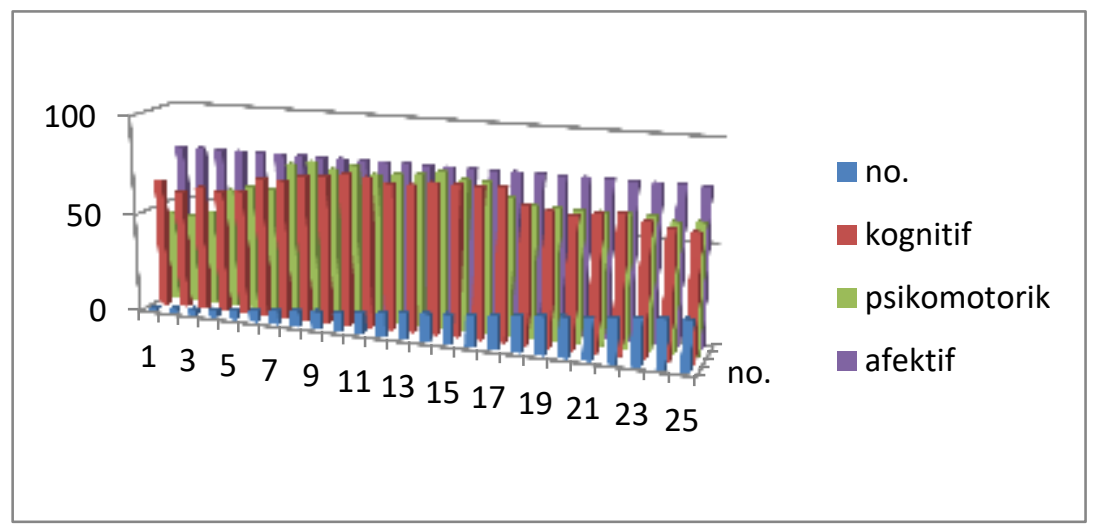

Diagram 1. Hasil kondisi awal

Madrasah Tsanawiyah Nurul Huda Dau sebagai ajuan awal untuk pembelajaran penelitian tindakan kelas, dimana banyaknya nilai 60 keatas belum sesuai KKM, hanya 10 siswa yang mampu pembelajaran yang nilainya layak, akhirnya peneliti memberi pembelajaran circuit learning dan bisa dilihat disiklus I:

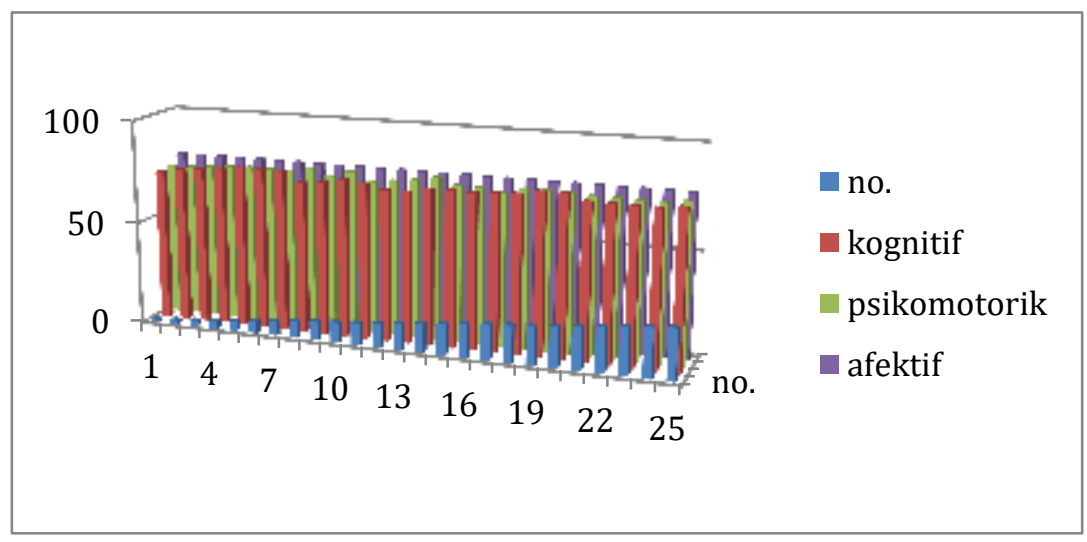

Diagram 2. Siklus 1

Disiklus I ada peningkatan pembelajaran yang cukup signifikan setelah diberi model pembelajaran circuit learning pada mata pelajaran senam lantai, dimana aspek psikomotorik meningkat saat pembelajaran 75, 52\%, dan kognitif 75, $42 \%$ pun mengalami kenaikan. Sebab materi senam lantai meroda dibutuhkan diskusi untuk memecahkan problem bagaimana praktik yang benar untuk gerakan meroda. Setelah ada peningkatan, peneliti masih kurang yakin dan diadakan siklus II dimana pembelajaran diatas rata- rata kkm dan berikut diagramnya. 


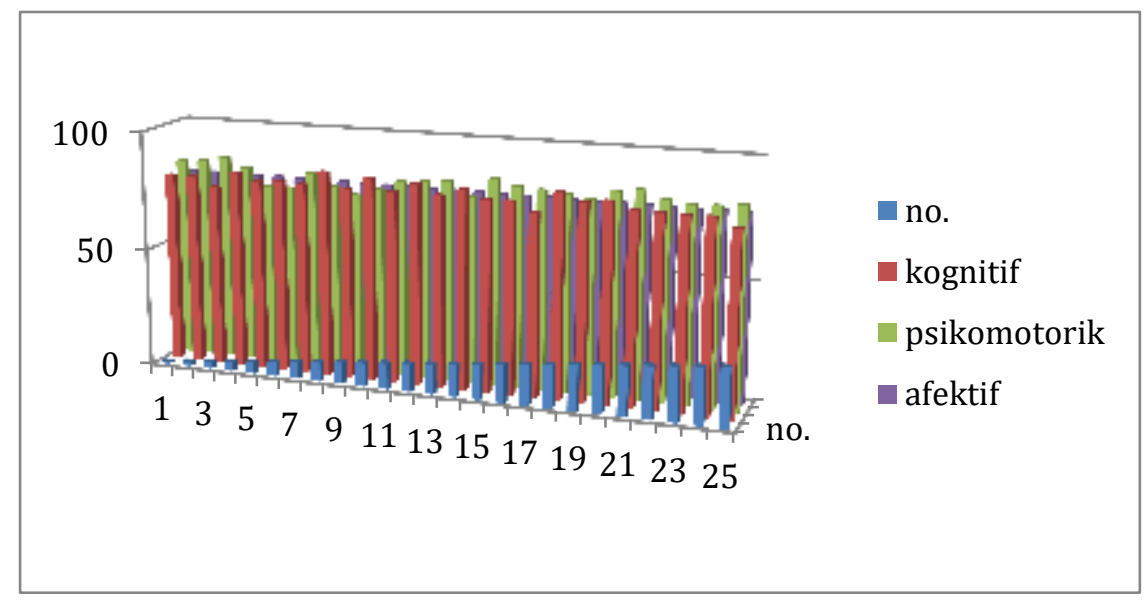

Diagram 3. Siklus II

Disiklus II sangat mengalami peningkatan dimana nilai kognitif rata- rata $80,8 \%$, dan nilai psikomotorik $81.96 \%$, dan afektif $78 \%$. Ini menandakan adanya kecocokan model cooperative learning tipe circuit learning dimana untuk pembelajaran senam gerak meroda sangat antusias dalam siswa, sebab perlunya peneliti sangat berinovasi memberikan bimbingan yang cukup dan baik serta mencapai sempurna

Pembahasan

Data studi awal yang diperoleh dari 25 siswa 10 siswa yang diatas kkm, disiklus I mengalami kenaikan dari 10 siswa sebelumnya sudah mencapai kkm dan bertambah 7 siswa tuntas $\mathrm{kkm}$ dalam pembelajaran. Dimana sebagai acuan circuit learning ini berhasil menambah kemajuan siswa dalam pembelajaran. Disiklus II adanya kemajuan pesat sehingga bisa tuntas untuk pembelajaran senam lantai meroda. Hal ini berkat semangat siswa serta model pembelajaran yang baru

\section{Simpulan}

Setelah mencapai hasil analisis data. Observasi dilakukan pada dua tahap, dimana siklus pertama dalam proses tindakan eksplorasi rata- rata yang diperoleh 25 siswa ialah 75,52\% aspek psikomotorik, 75,42\% aspek kognitif. Sebab siklus pertama belum memperoleh hasil yang maksimal, maka peneliti lanjut kesiklus kedua dalam proses tindakan eksplorasi setelah dikasih circuit learning dan data diperoleh 25 siswa ialah 81,96\% aspek psikomotorik, dan aspek kognitif mendapatkan 78\%. karena waktu penelitian dilakukan dua bulan penelitian ini cukup menggunakan dua siklus, hasil eksplorasi menunjukan adanya peningkatan sebanyak $74 \%$. dalam proses melalui belajar senam lantai meroda metode cooperative learning tipe circuit learning serta melalui dua tahap siklus.

\section{Daftar Pustaka}

Arikunto S. 2010. Metodologi Penelitian. Jakarta. Penerbit Renika Cipta

Aeniah, B. (2020). peningkatan Prestasi Belajar IPS Materi Mengenal Cara Menghadapi Bencana Alam Dengan Model Cooperative Type Circuit Learning Siswa Kelas VI Semester I SDN 
Creating Productive and Upcoming Sport Education Profesional Hmzanwadi University

Vol.4, No.2, Desember 2021, Hal. 204-209

e-ISSN 2614-8781

Batu Kembar Kecamatan Janapria Tahun Pelajaran 2015/2016. JISIP (Jurnal Ilmu Sosial dan Pendidikan) , 4 (1).

Ertanti, D. N., \& Nugroho, D. Penerapan Model Pembelajaran Cooperative Learning Type Group Investigation Untuk Meningkatkan Hasil Belajar Guling Belakang. Phedheral, 14(1), 2133.

Halim, A. F. (2012). Meningkatkan keterampilan meroda pada pembelajaran senam lantai siswa kelas VIII B SMP Negeri 7 Malang menggunakan pendekatan bermain. Meningkatkan keterampilan meroda pada pembelajaran senam lantai siswa kelas VIII B SMP Negeri 7 Malang menggunakan pendekatan bermain/Arif Faisol Halim.

Hanafiah, dkk. 2010. Konsep Strategi Pembelajaran . Refika Aditama. Bandung

Khalilurrahman, K., Haetami, M., \& Hidasari, F. P. Keterampilan Senam Lantai Melalui Pembelajaran Kooperatif Di Madrasah Tsanawiyah Hidayatul Muslimin I. Jurnal Pendidikan DAN Pembelajaran Khatulistiwa, 8(12).

Margono A. 2009. Senam. Surakarta: UNS Press

Putra, CA, \& Setiawan, MA (2019). Penerapan Model Pembelajaran Circuit Learning Berbantuan Media Power Point Terhadap Hasil Belajar IPS. Jurnal Bidang Pendidikan Dasar, 3 (1), 1-6.

Pertiwi, E. S., Budi, D. R., Hidayat, R., Widanita, N., \& Kusuma, I. J. (2021). Hubungan Kekuatan Otot Lengan, Kelentukan dan Keseimbangan Dengan Kemampuan Gerakan Senam Meroda. Physical Activity Journal (PAJU), 2(2), 146-158.

Pratiwi, R. N. (2021). Pengembangan model-model latihan rangkaian gerak dasar pada senam lantai melalui VCD untuk siswa kelas IX di SMP Negeri 18 Kota Malang. SKRIPSI Mahasiswa UM.

Paranna, M., \& Airlanda, GS (2020). Pengaruh Model Pembelajaran Circuit Learning Berbantu Multimedia Dan Media Sederhana Terhadap Kreativitas Siswa. JRPD (Jurnal Riset Pendidikan Dasar) , 3 (1), 57-63.

Prakentristiari, N. K. L., Astra, I. K. B., \& Semarayasa, I. K. (2014). Penerapan Kooperatif Tipe Nht Untuk Meningkatkan Aktivitas Dan Hasil Belajar Senam Lantai. Jurnal Pendidikan Jasmani, Olahraga Dan Kesehatan Undiksha, 2(1).

Roji. (2004). Pendidikan Jasmani Untuk SMP. Jakarta : Erlangga

Rambe, RT (2011). Penerapan Model Pembelajaran Kooperatif Tipe Circuit Learning untuk Meningkatkan Aktivitas Belajar Siswa Pada Mata Pelajaran IPS dalam Memahami Materi Menghargai Peninggalan Sejarah Kelas IV SDN 006 Kecamatan Senapelan Pekanbaru (Disertasi Doktor, Universitas Islam Negeri Sultan Syarif Kasim Riau).

Racutisyah, D. (2016). Penerapan Media Audio Visual (Video) Terhadap Hasil Belajar Meroda Dalam Pembelajaran Senam Lantai (Studi Pada Kelas Viii Di Smp Negeri 2 Tempeh Kabupaten Lumajang). Jurnal Pendidikan Olahraga Dan Kesehatan, 4(1).

Sudrajat, M. A. (2013). Upaya meningkatkan keterampilan pembelajaran rangkaian teknik dasar senam lantai gerak meroda dan guling depan menggunakan metode part and whole untuk siswa kelas VIII A di SMP Negeri 2 Ngunut Kabupaten Tulungagung. Upaya meningkatkan keterampilan pembelajaran rangkaian teknik dasar senam lantai gerak meroda dan guling depan menggunakan metode part and whole untuk siswa kelas VIII A di SMP Negeri 2 Ngunut Kabupaten Tulungagung/Muhammad Akbar Sudrajat.

Sandari, F. R. (2012). Upaya meningkatkan keterampilan senam lantai guling depan menggunakan metode part-whole untuk siswa kelas Xc di SMA Negeri 1 Garum Kabupaten Blitar. Upaya meningkatkan keterampilan senam lantai guling depan 
menggunakan metode part-whole untuk siswa kelas Xc di SMA Negeri 1 Garum Kabupaten Blitar.

Setiawati, K. S., Parwata, I. G. L. A., \& Suratmin, S. (2020). Pengaruh Model Pembelajaran Dan Minat Belajar Terhadap Hasil Belajar Senam Lantai. Jurnal Penjakora, 7(1), 17-29.

Widianto, B. K. (2016). Penerapan Model Pembelajaran Cooperative Learning Tipe Group Investigasi Untuk Meningkatkan Hasil Belajar Meroda pada Siswa XI Akuntansi 1 SMK Negeri 1 Banyudono Boyolali Tahun Pelajaran 2015/2016.

Yusuf, Y. (2018). Peningkatan ketrampilan senam lantai siswa kelas VI SDN Dempelan 01 melalui pembelajaran langsung dengan metode JIGSAW. Premiere Educandum: Jurnal Pendidikan Dasar Dan Pembelajaran, 8(1), 54-59. 